\title{
Uso de la ozonoterapia como tratamiento de patologías en pequeños animales
}

\section{Use of ozone therapy as a treatment of pathologies in small animals}

\section{Uso da ozonioterapia como tratamento para patologias em pequenos}

\author{
animais \\ Herrera Parra Oscar Javier ${ }^{1}$ y Fuentes Reyes Edgar Edilberto ${ }^{2}$ \\ ${ }^{1}$ Médico Veterinario Zootecnista, Universidad de los Llanos y \\ ${ }^{2}$ Médico Veterinario Zootecnista, MSc., PhD., Docente Universidad de los Llanos \\ efuentes@unillanos.edu.co
}

Recibido 12 de Diciembre 2018, Aceptado 24 de Abril 2019

\section{RESUMEN}

En este trabajo monográfico se realiza una revisión de literatura acerca del estado actual del uso de la ozonoterapia en la clínica de pequeños animales. Inicialmente el ozono fue utilizado para el tratamiento y potabilización del agua y desde 1915 comenzó a ser usado como agente terapéutico en personas por su acción germicida. En la medicina humana se ha reconocido los efectos que produce el ozono en el organismo, tales como el equilibrio en el balance REDOX, mejora del metabolismo del oxígeno, efecto inmunomodulador, propiedades antiinflamatorias, acción analgésica, promotor de la cicatrización y acción germicida. Todas sus propiedades están directamente relacionadas con la generación de productos secundarios, especies reactivas del oxígeno (ROS) y productos de la oxidación lipídica (LOPs), que en cantidades adecuadas producen dichos procesos biológicos. En la clínica de pequeños animales la ozonoterapia está siendo utilizada principalmente en el tratamiento de enfermedades que afectan la piel, de tipo bacteriana, fúngica y ectoparasitaria. También se han realizado estudios de su eficacia en el manejo del dolor en patologías musculoesqueléticas, en especial las de carácter crónico. El ozono en la Medicina Veterinaria tiene un futuro prometedor y tiene un potencial grande para la realización de más estudios en pequeños animales. 
Palabras clave: Ozono, ozonoterapia, inmunomodulador, oxígeno, especies reactivas del oxígeno, productos de la oxidación lipídica.

\section{ABSTRACT}

In this monographic work a literature review is made on the current state of ozone therapy in the small animal clinic is carried out. Initially ozone was used for the treatment and purification of water and since 1915 began to be used as a therapeutic agent in people for their germicidal action. In human medicine the effects of ozone on the body have been recognized, such as balance in REDOX balance, oxygen metabolism improvement, immunomodulatory effect, anti-inflammatory properties, analgesic action, healing promoter and germicidal action. All of its properties are directly related to the generation of by-products, reactive oxygen species (ROS) and Lipid Oxidation Products (LOPs), which in adequate amounts produce such biological processes. In the small animal clinic, ozone therapy is being used mainly in the treatment of bacterial, fungal and ectoparasitic diseases affecting the skin. Studies have also been made of its efficacy in the management of pain in musculoskeletal conditions, especially chronic ones. Ozone in Veterinary Medicine has a promising future and has great potential for further studies on small animals.

Keywords: Ozone, ozone therapy, immunomodulator, oxygen, reactive oxygen species, lipid oxidation products.

\section{RESUMO}

Neste trabalho monográfico, é feita uma revisão da literatura sobre o estado atual do uso da terapia de ozônio na clínica de pequenos animais. Inicialmente, o ozônio era utilizado no tratamento e purificação da água e desde 1915 começou a ser utilizado como agente terapêutico nas pessoas por sua ação germicida. $\mathrm{Na}$ medicina humana reconheceu os efeitos que o ozônio no corpo, tais como o equilíbrio na balança REDOX, melhoria do metabolismo do oxigênio, efeito imunomodulador, anti-inflamatório, analgésico, cicatrização de promoção e ação germicida. Todas as propriedades estão directamente relacionados com a geração de produtos secundários, espécies reactivas de oxigénio (ROS) e os produtos de 
oxidação lipídica (LOPs) que produzem quantidades adequadas de tais processos biológicos. Na clínica de pequenos animais a terapia de ozônio está sendo utilizada principalmente no tratamento de doenças que afetam a pele, bactérias, fungos e ectoparasitas. Estudos de sua eficácia no manejo da dor em patologias musculoesqueléticas, especialmente aqueles de natureza crônica, também foram realizados. O ozônio em medicina veterinária tem um futuro promissor e tem grande potencial para realizar mais estudos em pequenos animais.

Palavras-chave: Ozônio, ozonioterapia, imunomodulador, oxigênio, espécies que reagem ao oxigênio, produtos de oxidação de lipídios.

\section{INTRODUCCIÓN}

Se ha comprobado que el ozono tiene la capacidad de eliminar agentes patógenos, ésta propiedad fue usada para el tratamiento y potabilización del agua para consumo humano. La ozonoterapia en medicina es una realidad, durante muchos años se empleó por su efecto germicida y actualmente se utiliza como complemento terapéutico para diferentes enfermedades relacionadas con el estrés oxidativo incluido el dolor crónico. Las aplicaciones médicas del ozono se basan en aprovechar su alta capacidad oxidante frente a biomoléculas, generando un estrés controlado que activa respuestas antioxidantes endógenas.

Siendo la ozonoterapia una herramienta terapéutica sencilla y económica proporciona un potente arsenal terapéutico al veterinario permitiéndole abordar enfermedades antes solo tratables a un alto costo. El ozono se disuelve en el plasma sanguíneo, fluidos extracelulares, en la delgada capa de agua que cubre la piel y en mucosas del intestino, vagina, entre otras, por lo que es capaz de reaccionar con gran cantidad de sustancias biológicas hasta provocar su oxidación completa; entre estas sustancias se encuentran las proteínas, las glicoproteínas, ácidos como: ascórbico, úrico y grasos poli-insaturados que forman parte de los complejos lipoproteicos del plasma y de las capas de las membranas celulares (Scwhartz y Martínez, 2011). El resultado de la interacción del ozono con todos estos elementos biológicos es la producción de metabolitos secundarios, los cuales 
le confieren al ozono propiedades medicinales importantes en el tratamiento de enfermedades (Menéndez, 2008).

El ozono era conocido desde la antigüedad, el griego "ozein" significa gas que huele, la literatura científica documenta que la primera mención del ozono fue en 1785 por el físico holandés Martinus Van Marum al percibir un olor peculiar que se generaba cerca de las máquinas electroestáticas, pero fue gracias al químico Alemán Christian Friedrich Schönbein que, en mayo de 1840, usando una pila voltaica en presencia de oxígeno, notó el surgimiento de un gas con un olor "eléctrico y picante", por lo cual se le otorga su nombre (González, 2012).

En el año 1857 se logró por primera vez la formación de ozono de manera artificial por Werner von Siemens quien, mediante la construcción del tubo de superinducción genero un poco de ozono; años después, por sus propiedades bactericidas, se comenzó a fabricar utilizando una máquina para obtener agua potable (Bocci, 2005). Más tarde, por su poder antiséptico y amplio espectro de acción; fue utilizado principalmente en la potabilización del agua. En 1870 el médico alemán Lender realizó la primera publicación sobre los efectos biológicos en el agua, en 1915, el Dr. O. Woolf, cirujano del Ejército Alemán utiliza el ozono para tratamiento de las heridas infectadas en la Primera Guerra Mundial (González, 2012). En el año 1958 se construye el primer generador de ozono medicinal con marca registrada, el Ozonosan PM 58, que permitía una dosis exacta de la mezcla oxigeno-ozono (Scwhartz y Martínez, 2011).

\section{¿QUÉ ES EL OZONO?}

El ozono es un gas cuya estructura molecular está compuesta por tres átomos de oxígeno $\left(\mathrm{O}_{3}\right)$ y se forma naturalmente en las capas altas de la atmósfera, mediante la modificación estructural del oxígeno (Bocci, 2005). Este compuesto es importante en el equilibrio ecológico de la tierra, puesto que tiene la capacidad de absorber gran parte de las radiaciones ultravioletas provenientes del sol, las tres fuentes de energía por las cuales se puede formar ozono son: la electrólisis química, las descargas eléctricas y las radiaciones de luz UV (Scwhartz y Martínez, 2011). 
Menéndez, (2008) menciona que las radiaciones de elevada energía que emanan del sol descomponen las moléculas de oxígeno presentes en el aire en átomos libres, algunos de los cuales se combinan con otras moléculas de oxígeno para constituir el $90 \%$ del ozono atmosférico, ubicándose en una franja entre los 15 y 55 $\mathrm{km}$ arriba de la superficie de la Tierra.

\section{FORMACIÓN ARTIFICIAL DEL OZONO}

La formación artificial del ozono es el resultado de un proceso de modificación molecular que sufre el oxígeno, por acción directa de una descarga eléctrica silenciosa, de alta frecuencia y voltaje sobre su estructura (Rubiano, 2015). El oxígeno se encuentra formado por dos átomos que en sus núcleos presentan protones (carga positiva) y neutrones (cargas positiva y negativa) que giran alrededor de cada núcleo; tres órbitas de electrones de cargas negativas, la primera órbita presenta dos electrones, la segunda ocho y la tercera seis electrones, de los cuales dos son compartidos con el otro átomo del oxígeno, en esta unión es donde el aparato generador de ozono produce una descarga eléctrica separándolos y transformándolos en radicales libres que se unen a moléculas de oxígeno $\left(\mathrm{O}_{2}\right)$ formando la molécula de ozono $\left(\mathrm{O}_{3}\right)$ (González, 2012). La producción de ozono terapéutico requiere de oxígeno medicinal, ésta mezcla debe ser producida in situ para cada aplicación y en ella no debe haber más de un $5 \%$ de ozono. El circuito inicia con un flujo regulado desde una bala de oxígeno, y viaja hasta el equipo generador de ozono; donde recibe la descarga eléctrica generando ozono, el cual sale a través de una manguera (Hidalgo y Torres, 2013).

La molécula de ozono es sensible a los cambios medio ambientales, por ello se recomienda su administración inmediata, la concentración de este gas depende estrictamente de la temperatura a la que se encuentra expuesta, por ejemplo: a una temperatura de $20^{\circ} \mathrm{C}$ su concentración se reduce a la mitad en 40 minutos, a $30^{\circ} \mathrm{C}$, este mismo proceso toma 25 minutos; por otra parte si se expone a bajas temperaturas su concentración no se ve tan afectada, a $-50^{\circ} \mathrm{C}$ su concentración se disminuye a la mitad sólo después de tres meses (Bocci, 2005). 


\section{ACCIÓN BIOLÓGICA DEL OZONO MEDICINAL}

La reacción del ozono con diferentes moléculas y la posterior formación de metabolitos secundarios implican dos procesos fundamentales, el primero consta que parte del gas es consumido durante la oxidación del grupo sulfhidrilo $(\mathrm{SH})$ de las proteínas, las glicoproteínas y los ácidos ascórbico y úrico que como resultado generan varias especies reactivas del oxígeno (ROS, por sus siglas en inglés) que desencadenaran diversas vías bioquímicas; los ROS incluyen varios radicales como el anión superóxido $\left(\mathrm{O}_{2}{ }^{-}\right)$, el monóxido de nitrógeno $(\mathrm{NO})$, el peroxinitrito $\left(\mathrm{O}=\mathrm{NOO}{ }^{-}\right)$, el radical hidroxilo y el ácido hipocloroso $(\mathrm{HClO})$. El segundo proceso es tardío y se le denomina peroxidación lipídica, en este caso están implicados ácidos grasos (particularmente el ácido araquidónico presente en triglicéridos y quilomicrones del plasma); como resultado se produce otro ROS, conocido como peróxido de hidrógeno $\left(\mathrm{H}_{2} \mathrm{O}_{2}\right)$ y aldehídos conocidos como Productos de la Oxidación Lipídica (LOPs, por sus siglas en inglés) (Bocci, 2005).

\section{EFECTOS DEL OZONO MEDICINAL}

El ozono es altamente reactivo y todas sus propiedades están directamente relacionadas con la generación de productos secundarios que, en cantidades adecuadas, producen efectos biológicos tales como equilibrar el balance REDOX, mejorar el metabolismo del oxígeno, inmunomodulación, tienen propiedades antiinflamatorias y analgésicas, promueve la cicatrización con una acción germicida. Los LPOs del endotelio y otros órganos hace una regulación positiva de proteínas y enzimas antioxidantes y estimula la liberación de células madre (Bocci, 2005).

\section{EQUILIBRIO EN EL BALANCE REDOX}

El cuerpo produce radicales libres de forma natural, éste es un mecanismo utilizado por las células del sistema inmune para destruir bacterias y virus, no obstante, existen elementos en el ambiente que pueden promover una mayor producción de radicales libres, entre los que se encuentran la polución industrial, el tabaco, la radiación, los medicamentos, los aditivos químicos en los alimentos y pesticidas; a éste proceso se le denomina oxidación (Menéndez, 2008). Cuando se rompe el 
equilibrio que existe entre los radicales libres y las enzimas endógenas antioxidantes se produce un fenómeno denominado estrés oxidativo, el cual puede causar lesiones en tejidos llevando a la muerte celular (Bocci et al., 2007). El uso del ozono restablece el balance REDOX intracelular, incrementando la actividad de estas enzimas endógenas (glutatión peroxidasa, glutatión reductasa, catalasa y superóxido dismutasa), disminuyendo el estrés oxidativo (Borrego et al., 2004). También se ha buscado manejar el ozono desde un enfoque profiláctico, mediante el pre-acondicionamiento oxidativo con el objetivo de favorecer el balance antioxidante-prooxidante mediante el aumento de la respuesta de los sistemas endógenos antioxidantes, y de esta manera preservar el estado REDOX celular (Zamora et al., 2005).

\section{EFECTO EN EL METABOLISMO DEL OXÍGENO}

El ozono medicinal aumenta la oxigenación sanguínea actuando sobre las cadenas dobles de ácidos grasos insaturados de la capa fosfolipídica de la membrana eritrocítica lo cual conduce a la formación de peroxidasa, que tiene un importante papel en el metabolismo a través de los sistemas REDOX (reducción-oxidación), NADH/NAD (co-enzima nicotinamida adenina dinucleótido que lleva electrones de una reacción a otra) y GSH/GSSG (glutatión reducido con poder antioxidante). La reacción de la peroxidasa con el glutatión incrementa la producción de 2,3 DPG (difosfoglicérido) e hidrogeniones facilitando la liberación de oxígeno a partir de la oxihemoglobina, principalmente en tejidos afectados por isquemia (González, 2012).

\section{EFECTO INMUNOMODULADOR}

Los diferentes efectos que produce el ozono medicinal en un organismo dependen de la dosis y/o concentración en la que se emplean, en condiciones controladas es un agente inductor de citoquinas dado que no es tóxico, no es antigénico y produce una respuesta inmune positiva (González, 2012). En el caso de su efecto inmunomodulador, la administración de dosis bajas de ozono puede reactivar el sistema inmune deprimido como consecuencia de diversas patologías (Scwhartz y 
Martínez, 2011). El efecto está dirigido a la línea leucocitaria, principalmente los monocitos y linfocitos $\mathrm{T}$; una vez éste haya realizado su efecto inductor, los leucocitos liberan pequeñas cantidades de citoquinas de manera controlada (Díaz et al., 2013).

En la regulación de la síntesis de citoquinas intervienen ciertos factores transcripcionales como NF-kB, favoreciendo los procesos de transcripción y transducción a nivel del ADN, actuando como promotor de este sitio (o serie de bases nitrogenadas) por donde ocurre la transcripción directamente de ADN a ARN, para conducir al incremento o supresión en la síntesis de alguna citoquina en particular, sea esta pro-inflamatoria o anti-inflamatoria (Figura 1) (Scwhartz y Martínez, 2012).

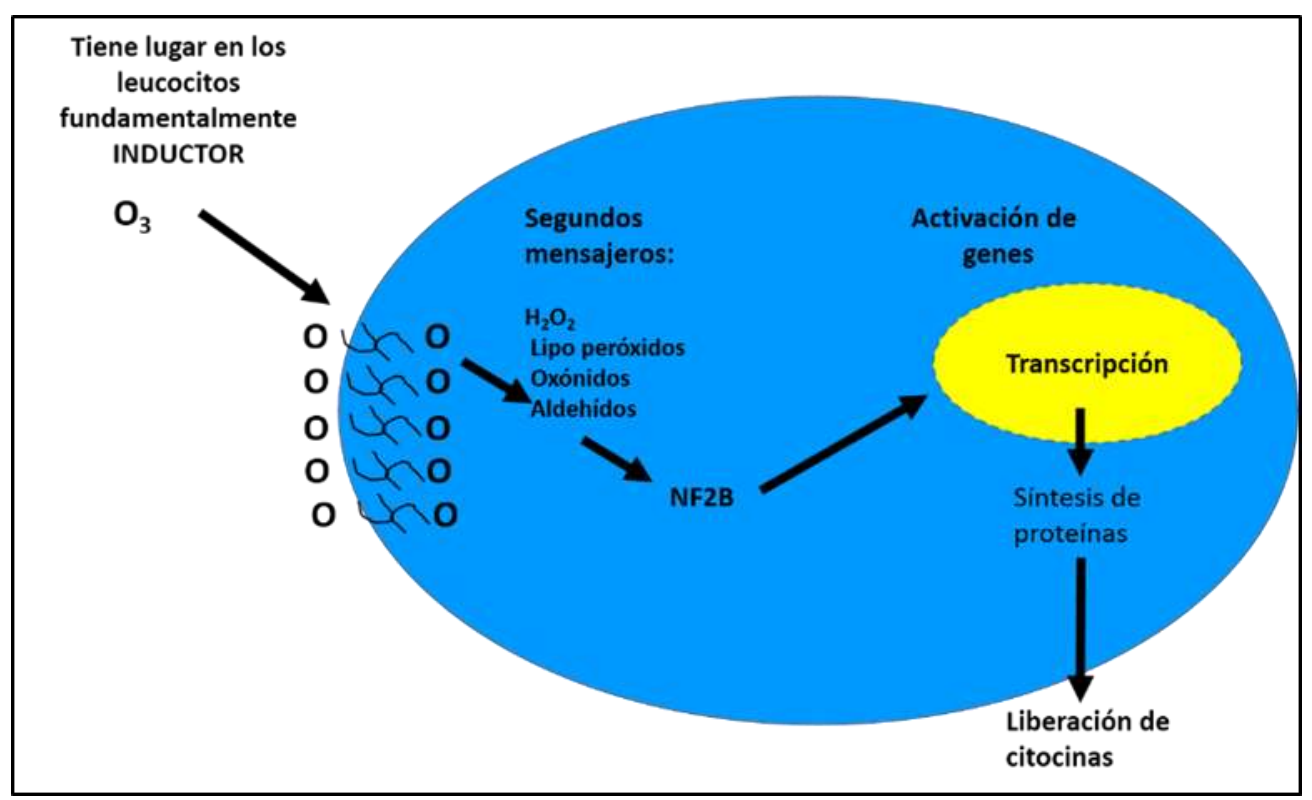

Figura 1. Mecanismo de acción del ozono como regulador de la síntesis de citoquinas (Scwhartz y Martínez, 2011).

Se ha demostrado la capacidad del ozono de regular a la interleucina (IL4) y de generar una pequeña estimulación del interferón gamma (IFN-v) y el factor de necrosis tumoral alfa (TNF- $\alpha$ ) aún en dosis reducidas (Larini y Bocci, 2005).

Resultados obtenidos mediante modelos experimentales han logrado demostrar la capacidad de la mezcla oxígeno-ozono de disminuir la respuesta de 
hipersensibilidad a un alérgeno, mediante la disminución de la síntesis de inmunoglobulina $\mathrm{G}(\mathrm{lg} \mathrm{G})$, con la consecuente disminución de la respuesta inflamatoria (Zayas et al., 2009).

\section{EFECTO ANALGÉSICO Y ANTIINFLAMATORIO}

Estos mecanismos de acción se han relacionado directamente con los efectos de múltiples metabolitos secundarios generados por el ozono. Scwhartz y Martínez, (2011) mencionan que los efectos moduladores pueden relacionarse a su modo de actuar sobre diversos blancos: 1) Menor producción de mediadores de la inflamación; 2) la oxidación (inactivación) de metabólicos mediadores del dolor; 3) mejora neta de la microcirculación sanguínea local, con una mayor entrega de oxígeno a los tejidos, imprescindible para la regeneración de estructuras anatómicas; y 4) la eliminación de toxinas y de manera general a la resolución del disturbio fisiológico que generó el dolor. Como es conocido las prostaglandinas son sustancias de carácter lipídico derivadas de ácidos grasos que juegan un papel en el proceso de respuesta inflamatoria, allí es donde el ozono interviene, disminuyendo su producción, por acción directa sobre el ácido araquidónico (Mondéjar y Rosas, 2016).

\section{ACCIÓN GERMICIDA}

Las propiedades germicidas del ozono se conocen desde el siglo XIX, demostrando capacidad para eliminar virus, bacterias y hongos por acción de sus metabolitos secundarios, los ROS, que reaccionan oxidando irreversiblemente a dichos agentes patógenos; la capacidad oxidante actúa sobre las paredes y membranas celulares bacterianas (Menéndez, 2008). En la acción contra bacterias y levaduras, el ozono posee un gran efecto sobre la membrana plasmática, produciendo oxidación proteica y lipídica y su posterior deterioro, los metabolitos generados por los procesos oxidativos causan una alteración en la funcionalidad de los orgánulos intracelulares, produciendo una pérdida del homeostasis de los agentes patógenos con su consecuente destrucción (Bocci, 2005). 
El efecto antivírico del ozono radica en la pérdida de las propiedades de la envoltura del virus y también en la inactivación de la transcriptasa inversa, por acción de sus metabolitos secundarios, de esta manera se inhibe los procesos de transcripción y síntesis proteica de los virus impidiendo su replicación (Schwartz, 2017).

Una gran cantidad de agentes infecciosos son susceptibles al efecto del ozono, entre estos las bacterias Gram negativas (Serratia marcescens, Escherichia coli, Pseudomonas aeruginosa, Klebsiella pneumoniae, Campylobacter, Salmonella), las Gram positivas (Sthaphylococcus aureus, Sthaphylococcus epidermidis, Streptococcus pyogenes, Enterococcus faecalis, Clostridium, Corynebacterium), y los micetos (Candida albicans) (Bocci, 2005).

\section{PROMOTOR DE LA CICATRIZACIÓN Y REGENERACIÓN DE TEJIDOS}

El ozono promueve la activación del factor de transcripción NF-kB, el cual regula la respuesta inflamatoria y el proceso de cicatrización, produciendo un aumento de los factores endógenos de crecimiento: el de fibroblastos (FGF), el derivado de plaquetas (PDGF), transformante- $\beta$ (TGF- $\beta$ ) y el del endotelio vascular (VEGF) que participan en la regulación de la epitelización, la formación de tejido de granulación y la neovascularización (Kim et al., 2009).

El plasma rico en plaquetas (PRP) es un material biológico autólogo, proveniente de la filtración de la sangre del paciente, que contiene varios factores de crecimiento importantes en proliferación y diferenciación celular, angiogénesis, síntesis y deposición de matriz extracelular (Roberto, 2013). El uso del (PRP) activado con ozono ha sido objeto de estudios relacionados con la regeneración de tejidos y la cicatrización, en este caso el ozono promueve la agregación plaquetaria y la liberación de factores con propiedades mitogénicas y quimiotácticas (Schwartz y Martínez, 2011). Re et al., (2010) reportaron que el ozono puede promover la agregación plaquetaria, particularmente cuando se usa la heparina como anticoagulante, y que la liberación de los factores anteriormente mencionados es dependiente de la dosis de ozono empleada en el plasma rico en plaquetas heparinizado. 


\section{LA OZONOTERAPIA EN MEDICINA VETERINARIA}

La ozonoterapia se ha presentado como una nueva alternativa terapéutica en el campo de la clínica veterinaria y se han reconocido los beneficios con el uso de este tipo de terapia no convencional en el tratamiento de diversas enfermedades que afectan a diversas especies (Vidal et al., 2009). En países como España, Brasil y Cuba la ozonoterapia ha comenzado a ser utilizada en veterinaria, buscando la motivación en los profesionales para realizar trabajos científicos y para implementarla en la práctica clínica (Vigna y Menéndez, 2007).

Por su relación costo/beneficio positiva, la ozonoterapia veterinaria se ha estado incorporando en la rutina clínica diaria de hospitales, tanto en pequeños como en grandes animales, otorgándole al médico veterinario un arsenal terapéutico de fácil aplicabilidad, el cual se puede ser combinado con otras terapias convencionales dándole al cliente una alternativa más económica (Vidal et al., 2009).

\section{VÍAS DE ADMINISTRACIÓN DEL OZONO EN PEQUEÑOS ANIMALES}

Básicamente las vías de administración del ozono medicinal se dividen en dos (Figura 2), puede ser de forma local o sistémica y también pueden usarse solas o en combinación con la finalidad de ejercer un mejor efecto (Colín, 2016).

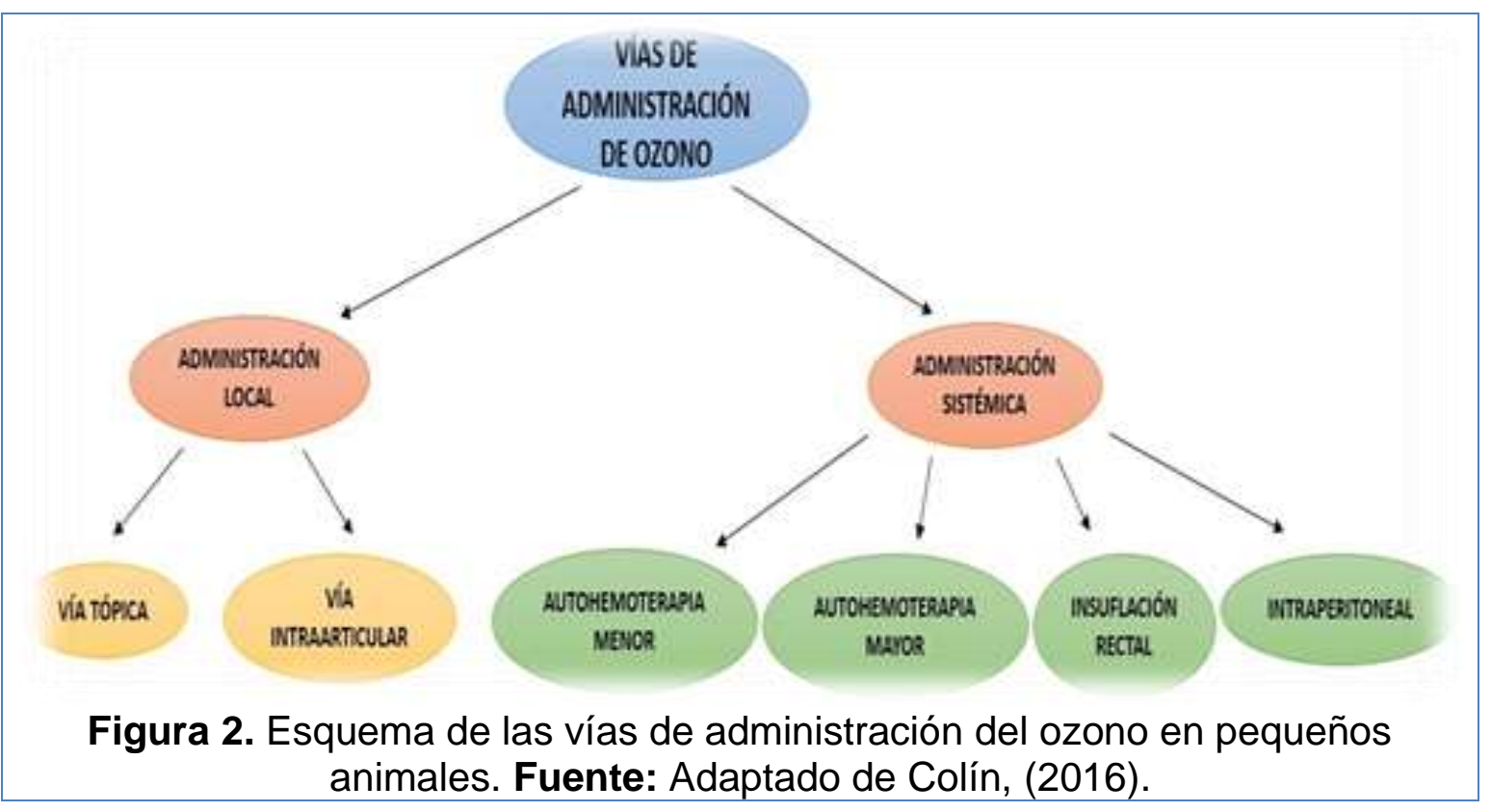




\section{VÍAS DE ADMINISTRACIÓN}

La vía tópica está indicada en casos de dermatitis, otitis, infecciones postquirúrgicas y en heridas, para lo cual se aplica directamente la mezcla de oxígeno/ozono en el sitio de la lesión, también se puede utilizar una bolsa la cual debe cubrir la lesión y posteriormente será llenada con la mezcla de gases (Figura 3). Se ha propuesto el uso de agua ozonizada para el tratamiento de lesiones en la piel bajo la afirmación de que la saturación de este líquido con ozono lo convierte en un buen vehículo de administración (Campoverde, 2014). El aceite de girasol y cremas ozonizadas, también son muy empleados de forma tópica por su poder germicida puesto que contiene aldehídos, ácidos carboxílicos, hidroperóxidos, ozónidos y otras especies peroxídicas (Camps et al., 2009). Díaz et al., (2006) mediante un modelo experimental en conejos afirmaron que este aceite de girasol tópico no es irritante para la piel, ni para las estructuras oculares y que tampoco tiene efecto sensibilizante al ponerse en contacto con la piel de los animales.
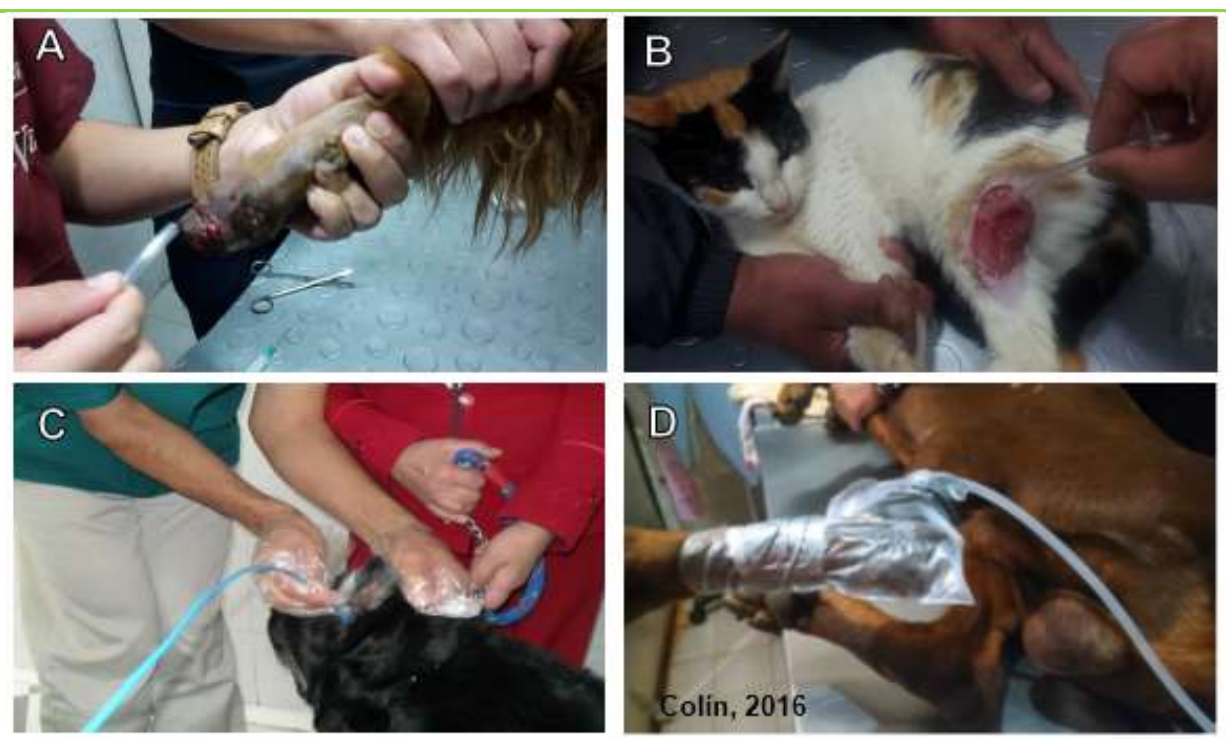

Figura 3. Administración de ozono por vía tópica. (A) canino, aplicación tópica de oxígeno/ozono directo en herida por guadaña. (B) felino, aplicación tópica de oxígeno/ozono en herida por traumatismo. (C) canino, aplicación ótica directa de oxígeno/ozono. (D) canino, aplicación de oxígeno/ozono con técnica de insuflación de bolsa.

Fuente: Figuras A, B y C: Autor, Figura D: Colín, (2016). 
La vía intramuscular es indicada en casos de manejo del dolor en patologías músculo-esqueléticas como osteoartritis y hernia discal, hasta procesos degenerativos como artrosis o espondilosis deformante (Hernández, 2013). Se infiltra la mezcla de oxígeno/ozono directamente en la articulación o se utiliza la técnica paravertebral intramuscular en el caso de la hernia discal (Figura 4) (Castrini y Prignacca, 2002).

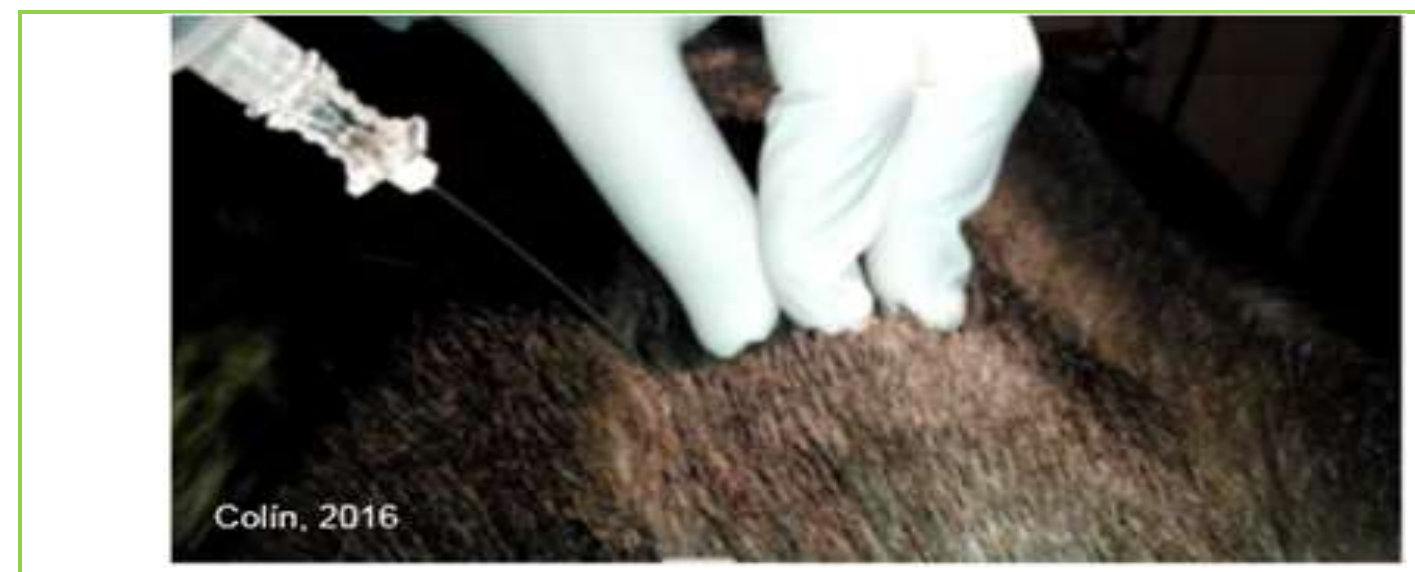

Figura 4. Administración de oxígeno-ozono de forma paravertebral en un canino Fuente: Colín, (2016).

El procedimiento debe ser realizado con una adecuada antisepsia de la zona y esterilidad de materiales como las jeringas y guantes, para este tipo de procedimiento no es necesario usar anestésicos, exceptuando a pacientes nerviosos o agresivos en donde se puede utilizar la anestesia local, o incluso la tranquilización (Colín, 2016). Se ha demostrado obtener respuestas positivas a esta terapia en problemas musculo-esqueléticos con evidentes mejoras en la movilidad en las primeras 24 horas posteriores a la aplicación (Ballardini, 2005). Se ha administrado el plasma rico en plaquetas (PRP) y el plasma pobre en plaquetas (PPP) autólogo ozonizado por vía intra-articular en problemas discales (en casos con protrusión, con roturas radiales o completas del anillo fibroso y con hernia discal, obteniendo una regeneración de la lesión y un efecto analgésico (Kirchner, 2012).

La vía sistémica se emplea en procesos alérgicos, en dermatitis y en el control de procesos inflamatorios, la autohemoterapia menor consiste en la extracción de una cantidad de sangre venosa del paciente, $1 \mathrm{ml}$ de sangre por cada $10 \mathrm{~kg}$ de peso 
vivo del animal, la cual es ozonificada y agitada suavemente por 2 minutos finalmente se aplica nuevamente al paciente por vía intramuscular (Colín, 2016). La autohemoterapia mayor mejora el aporte de oxígeno a los órganos y tejidos, modula el sistema inmune e incrementa la capacidad antioxidante del organismo, es utilizado en infecciones sistémicas, procesos virales y en enfermedades hemoparasitarias, (Menéndez, 2008). Se realiza la extracción de sangre del paciente, el 5\% del volumen total sanguíneo del paciente, puncionando la vena yugular y recolectándola en una bolsa para transfusión sanguínea con $13 \mathrm{~mL}$ de citrato de sodio al 3.8\%, paso seguido se administra la mezcla de oxígeno/ozono a la bolsa de transfusión, luego se mueve cuidadosamente la bolsa durante 2 minutos y finalmente se vuelve a transfundir la sangre al paciente (García et al., 2010).

La insuflación rectal, está indicada como coadyuvante en patologías intestinales de tipo viral, parasitario y bacteriano, además como estimulante del sistema inmunitario; se introduce una sonda plástica previamente lubricada por el ano, el diámetro de esta depende del tamaño del paciente y finalmente se procede a insuflar la mezcla oxigeno-ozono lentamente. La cantidad a administrar de la mezcla de gases varía según el tamaño del paciente, oscila entre 5 a $40 \mathrm{~mL}$ a una concentración de 20 a $40 \mu \mathrm{g} / \mathrm{mL}$ (Fierro, 2011).

La vía intraperitoneal es el método de administración de ozono más reciente y el menos utilizado, esta vía permite un alcance directo a órganos como hígado y bazo generando una disminución del estrés oxidativo en el tejido hepático y esplénico, puede ser usado como coadyuvante en procesos de peritonitis y se está empleando para estudios de tratamiento contra neoplasias (Zamora et al., 2007). Se carga una jeringa con oxígeno/ozono, se coloca la aguja de 21G, luego se realiza una punción en un punto fijo de la cavidad abdominal aproximadamente a dos centímetros caudal al ombligo y a un centímetro del lado lateral derecho de la línea media ventral, lentamente se va introduciendo la aguja hasta llegar a la cavidad peritoneal y finalmente se administra la mezcla de gases de 100 a 300 ml a una concentración de $50 \mu \mathrm{g} / \mathrm{mL}$, de ser necesario se puede realizar infiltración local con lidocaína (Colín, 2016). 


\section{CONTRAINDICACIONES DEL USO DEL OZONO}

La controversia que existe sobre el uso del ozono radica en los agresivos efectos de sus metabolitos, los ROS, estos productos derivados del oxígeno son altamente reactivos por su inestabilidad química y son capaces de dañar al ácido desoxirribonucleico (ADN), al actuar sobre las bases nitrogenadas, provocando modificaciones estructurales de las mismas (Bocci, 2005). La lipoperoxidación produce alteración de membranas y sus productos como el malondialdehído y el 4hidroxi-2-nonenal, son considerados como citotóxicos (Cárdenas y Pedraza, 2006). No obstante, la administración del ozono en la medicina es totalmente seguro ya que se utiliza en micro dosis, cuando ingresa al organismo en aproximadamente un minuto parte de las especies reactivas del oxígeno producidas por el ozono son consumidas por el sistema antioxidante presente en los fluidos biológicos, de esta manera se puede obtener efectos biológicos positivos y de manera controlada sin afectar al organismo. La vía inhalada e intravenosa están contraindicadas, así sea en micro dosis, produce lesiones tanto al epitelio de las vías respiratorias altas como al de las bajas, además es importante evitar que el área de trabajo se llene del gas (Bocci et al., 2009). En pacientes que presentan simbléfaron la terapia de ozono también está contraindicada debido a la estimulación de fibroblastos que éste produce, lo cual empeoraría la condición ocular (Vigna y Menéndez, 2007).

\section{ESTUDIOS SOBRE LA EFICACIA DE LA OZONOTERAPIA}

Camps et al., (2009) evaluaron la efectividad del aceite de girasol con ozono en 20 caninos diagnosticados con piodermitis, causado por Staphylococcus intermedius, se formaron cuatro grupos experimentales ( $A, B, C$ y $D$ ), al grupo $A$ se le administró una vez al día este aceite, al $B$ dos veces, al $C$ gentamicina una vez al día y al $D$ gentamicina dos veces, la duración del tratamiento fue de siete días para todos los casos, los resultados arrojaron una respuesta positiva a la terapia con el aceite, principalmente el grupo $B$ que tuvo un promedio de recuperación de 4.2 días, aunque existe variaciones entre la media de recuperación de los grupos $A$ y $B$, en el séptimo día de tratamiento, el $100 \%$ de los animales de ambos grupos estaban recuperados, a diferencia del grupo C y D (Tabla 1), así se confirma la efectividad 
del uso tópico con aceite en procesos infecciosos como la piodermitis, comparado con la efectividad de la gentamicina.

Tabla 1. Recuperación en días para los tratamientos

\begin{tabular}{cccc}
\hline Grupos & $\begin{array}{c}\text { Total animales } \\
\text { tratados }\end{array}$ & $\begin{array}{c}\text { Días para la } \\
\text { recuperación }\end{array}$ & $\begin{array}{c}\text { Total de recuperados } \\
\text { a los 7 días (\%) }\end{array}$ \\
\hline A & 5 & 6.0 & 100 \\
B & 5 & 4.2 & 100 \\
C & 5 & 8.8 & 0 \\
D & 5 & 7.2 & 80 \\
\hline
\end{tabular}

Fuente: Camps et al., (2009).

Camps et al., (2012) realizaron un estudio in vitro e in vivo para evaluar el nivel de efectividad de girasol con ozono para controlar el ectoparásito Psoroptes cunículi, que afecta a los conejos, para el primero se colectaron 150 ácaros adultos, los cuales se dividieron en tres cajas de Petri con 50 parásitos en cada una, en la primera caja se aplicó aceite con ozono (oleozon), en la segunda caja cipermetrina al $30 \%$ y en la tercera caja no se realizó ningún tratamiento (grupo control). Para el estudio in vivo se utilizaron 30 conejos adultos diagnosticados con sarna psoróptica, que se dividieron en tres grupos de 10 animales cada uno y se le administró el mismo tratamiento que en el in vitro (Grupo 1 oleozon, grupo 2 cipermetrina al 30\% y grupo 3 sin tratamiento). En el estudio in vitro se demostró una mayor efectividad del aceite con ozono, mostrando un porcentaje de mortalidad en los ectoparásitos más alto durante las horas de observación y donde el 100\% habían muerto a las 36 horas, mientras que con la cipermetrina el $100 \%$ de los ácaros murieron hasta pasadas las 72 horas. En cuanto al estudio in vivo se observó una recuperación del $100 \%$ de los animales tratados con oleozon a los 15 días, mientras que en el grupo tratado con cipermetrina solo el $70 \%$ de los animales se recuperaron en el mismo tiempo (Figura 5), de esta forma determinó la gran eficacia del aceite ozonizado contra ectoparásitos como el Psoroptes cunículi. 


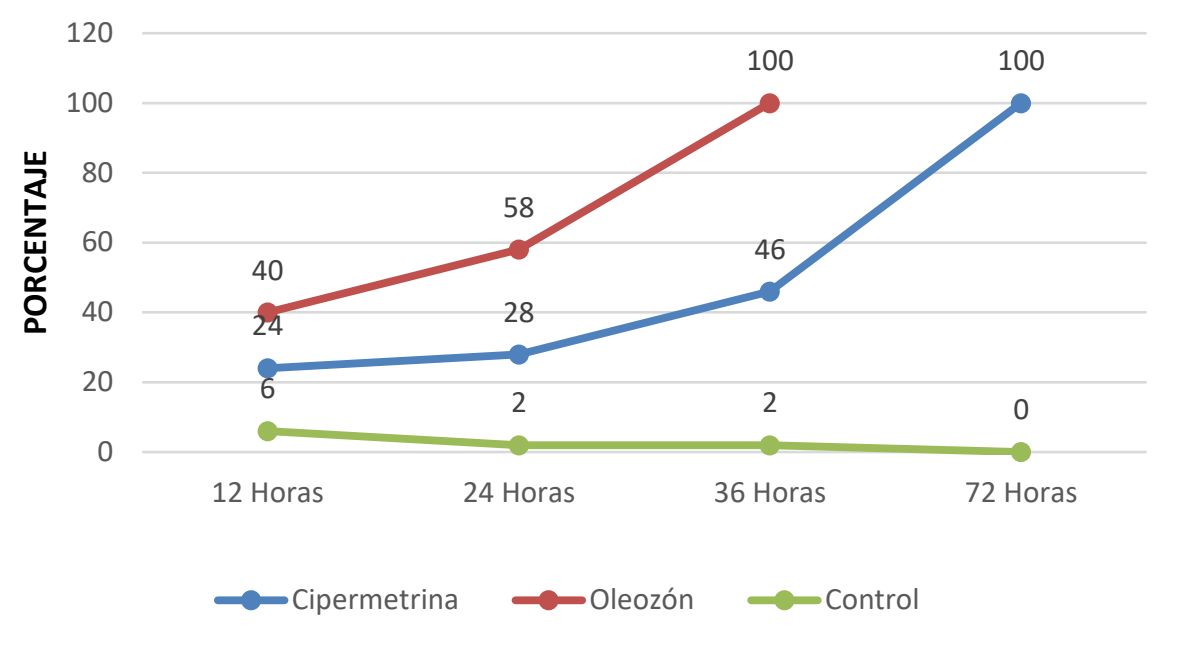

Figura 5. Acaros muertos por los tratamientos

Zamora et al., (2007) realizaron una investigación para evaluar la efectividad de la mezcla de oxígeno/ozono combinado con levofloxacina en un modelo de sepsis peritoneal en ratas; se conformaron cinco grupos de nueve ratones cada uno. La sepsis peritoneal fue inducida mediante una inyección intraperitoneal de una disolución de materia fecal extraída del ciego de una rata donante, observados hasta las 240 horas, monitoreándose la mortalidad, durante las primeras horas, los grupos tratados con levofloxacina y el de solamente ozono mostraron un comportamiento similar, a las 240 horas, se observó mayor supervivencia de los animales tratados con el antibiótico y ozono en comparación con los demás tratamientos donde se utilizó solo levofloxacina o solo ozono y el control que no recibió tratamiento. Con estos resultados se demuestra la efectividad que se puede obtener con la ozonoterapia en conjunto con la antibioticoterapia en un modelo de sepsis, demostrando también que puede ser más beneficioso el uso de terapias combinadas, que el uso del ozono como único plan terapéutico.

Vigna y Menéndez, (2007) realizaron un estudio para evaluar la efectividad del aceite de girasol ozonizado en colirio en enfermedades oftalmológicas en 59 gatos de diferente edad y origen con las siguientes enfermedades: Queratoconjuntivitis herpética, queratoconjuntivitis herpética, queratoconjuntivitis mixta por herpes virus, Chlamidiophila felis y Myicoplasma, úlcera corneal profunda por diferentes causas 
(herpética y traumática) y úlcera corneal por diversas causas tratada con injerto conjuntival ozonizado. Los resultados obtenidos en los pacientes con queratoconjuntivitis herpética y tratados con este colirio, administrado mediante una posología de dos gotas en cada ojo tres veces al día, mostraron una mejoría temprana, entre 5 a 6 días.

Los gatos con conjuntivitis por Chlamidiophila felis fueron tratados con dicho colirio, dos gotas en el fórnix de la conjuntiva cada ocho horas; después de sólo tres días de tratamiento todos los gatos, incluyendo los refractarios a los antibióticos, mostraron una gran mejora y después de 10 días de terapia todos los gatos fueron completamente curados. Los animales con queratoconjuntivitis mixta fueron tratados con el colirio, dos gotas cada 8 horas, además de tropicamida $0.12 \%$ (una gota dos veces al día) para evitar sinequias; después de 6 días de terapia el edema desapareció (Figura 6) y después de 15 días se registró la resolución completa de los síntomas con la cicatrización de las úlceras corneales herpéticas.
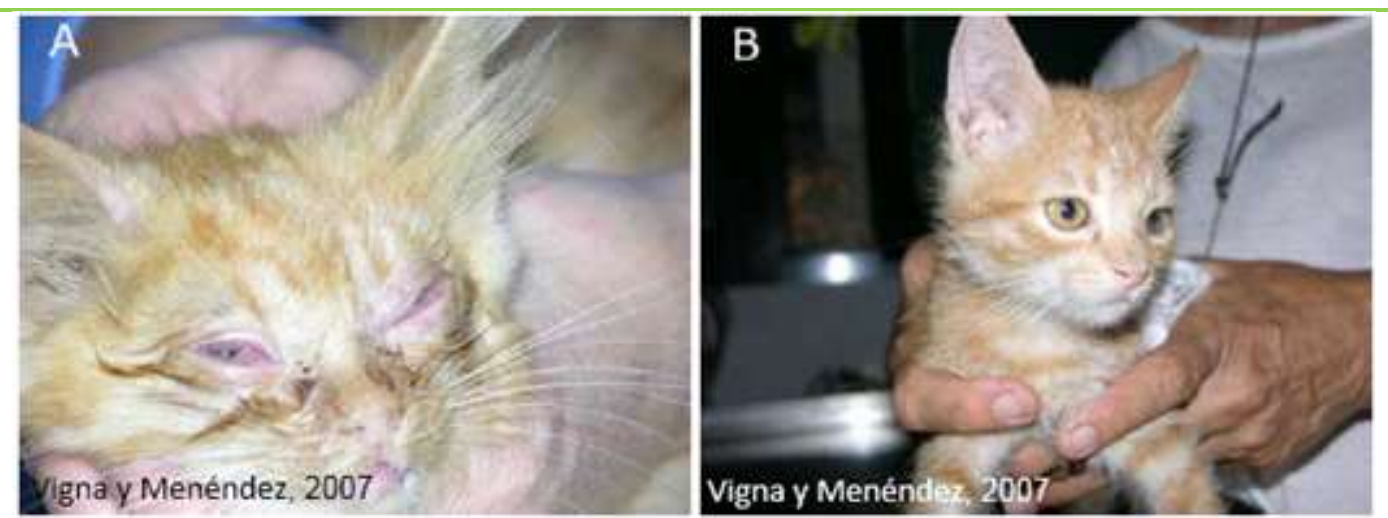

Figura 6. Evolución de un paciente felino con queratoconjuntivitis mixta, tratado con aceite de girasol ozonizado. Fuente: Vigna y Menéndez, (2007).

En el caso de las úlceras corneales se trataron dos perforadas, un descemetocele y cuatro úlceras profundas, la terapia consistió en colirio de girasol ozonizado, tres gotas cada 6 horas y tropicamida $0.12 \%$ una gota cada 8 horas, se obtuvo una cicatrización completa para las úlceras profundas en 7 a 9 días, para el descemetocele en 7 días, mientras que para las úlceras perforadas después de 10 
días la cicatrización de la córnea y en 30 días tenía una apariencia más natural (Figura 7).

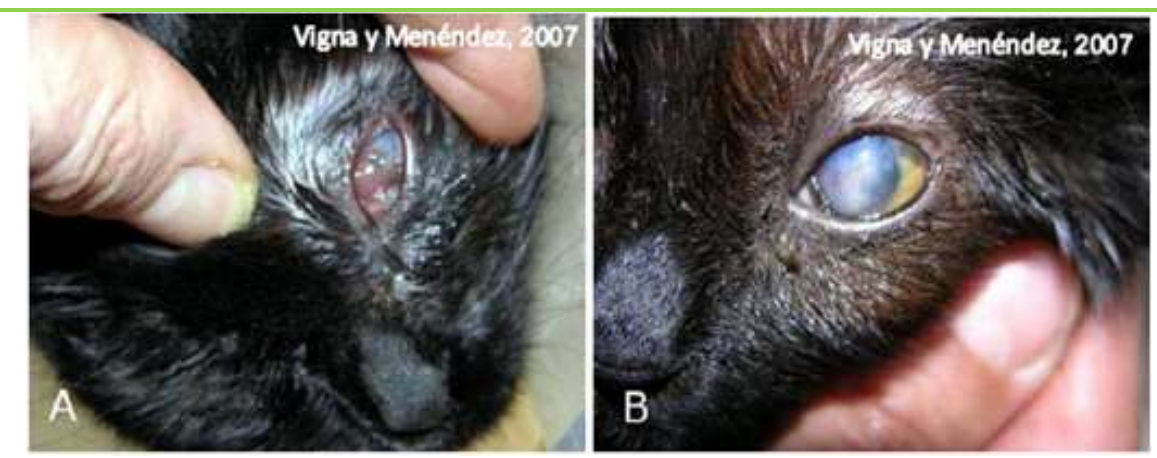

Figura 7. Evolución de una úlcera perforada en un felino tratado con aceite de girasol ozonizado. Fuente: Vigna y Menéndez, (2007).

En los animales con úlceras y con injertos conjuntivales, un gato con luxación de la lente cristalina en la cámara anterior y con consecuente pérdida de tejido corneal, fue tratado 6 veces al día con tres gotas colirio de girasol con ozono sobre el injerto y tropicamida $0.12 \%$, una gota cada ocho horas, después de 48 horas el injerto consiguió vascularización, después el tratamiento con ozono, la córnea se volvió transparente y se conservó el ojo. En tres gatos con úlcera perforada colagenolítica muy grande (uno de ellos con luxación y eyección de lente) aplicaron el injerto pediculado tratando la zona tres veces al día con tres gotas de aceite ozonizado, después de cuatro días cortaron el pedículo, continuando la terapia con tres gotas por cuatro veces al día en el injerto libre, el cual consiguió vascularización en dos días y en 10 días se obtuvo una integridad corneal (Figura 8).

García et al., (2010) realizaron un reporte de caso de un paciente canino de dos años diagnosticado con Ehrlichia spp., mediante la visualización de mórulas en una muestra de sangre de la oreja del animal puesta bajo microscopio óptico. Esta paciente fue sometida a una autohemoterapia mayor ozonizada; se recolectó el 5\% del volumen total de sangre, en este caso $80 \mathrm{ml}$, puesto que la paciente pesaba 20 $\mathrm{kg}$ (el volumen de sangre total corresponde al $8 \%$ del peso vivo), se colocó la sangre transfusional en una bolsa estéril, que contenía $13 \mathrm{ml}$ de citrato de sodio a 3.8\%, la mezcla oxígeno/ozono fue introducida a la bolsa en proporción 1:1 
homogenizándola de manera lenta y constante, la sangre fue devuelta al animal, este proceso se realizó dos o tres veces por semana. Los resultados de los cuadros hemáticos, antes y después del tratamiento, evidencian una respuesta positiva a la terapia (Tabla 2), el volumen plaquetario también mostró un incremento considerable al poco tiempo de iniciado las autohemoterapias y no se encontraron mórulas de Ehrlichia spp. De esta forma se confirmó la eficacia de la autohemoterapia mayor con ozono frente a hemoparásitos, como la Ehrlichia spp. Cabe resaltar que debería realizarse estudios más a fondo y con un número de casos más grande, para observar los diferentes tipos de respuesta al tratamiento.

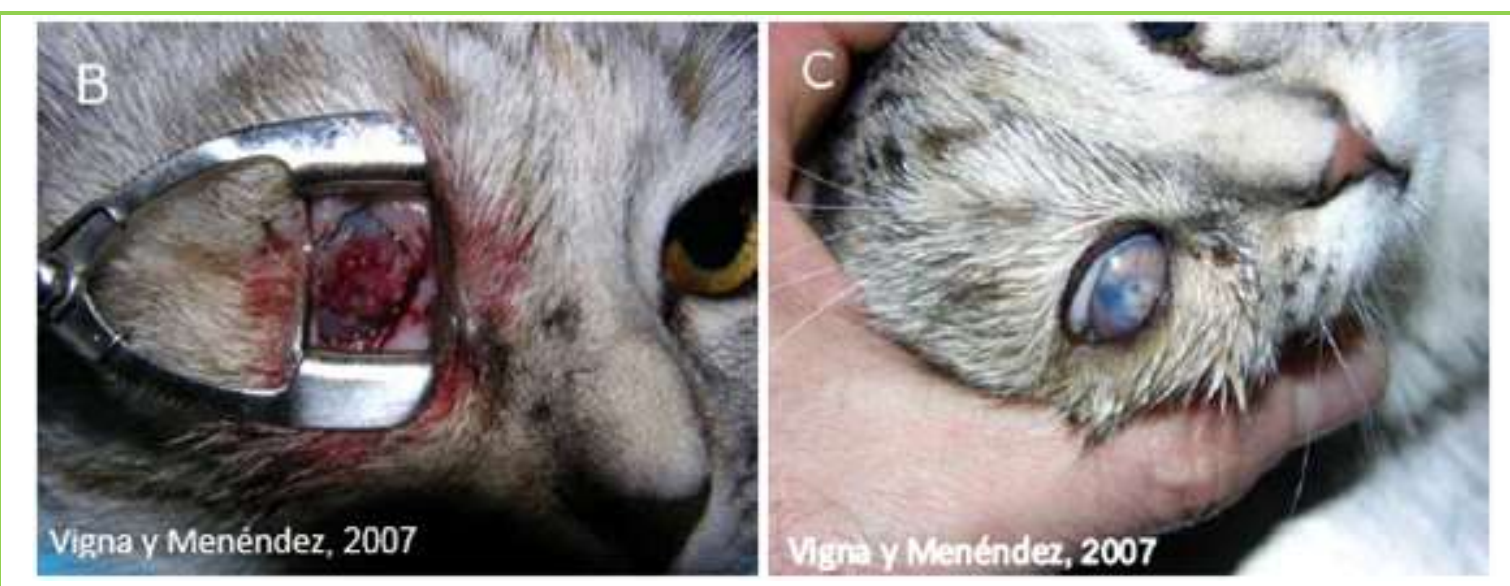

Figura 8. Evolución de paciente felino con injerto pediculado y tratado con aceite de girasol ozonizado. Fuente: Vigna y Menéndez, (2007).

En el estudio realizado por Hernández, (2013) se utilizó el ozono y los factores de crecimiento ozonizados en lesiones osteoartríticas en caninos divididos en dos grupos (Tabla 3) y se encontró que al segundo día de la primera sesión los perros del grupo 1 mostraron una respuesta positiva, después de la segunda sesión el 45\% de los perros mostraron una clara mejoría y después de la tercera sesión el dolor a la palpación desapareció en el $85 \%$ de los perros. En el grupo 2 el dolor desapareció en más de la mitad de los animales pasadas las 24 horas, finalizado los tratamientos los demás, excepto uno en donde sólo se disminuyó el dolor, se habían curado. Demostrando la efectividad de la terapia de ozono y de los factores de crecimiento ozonizados en el tratamiento de patologías musculo-esqueléticas, permitiendo una mejoría y mejor calidad de vida para los pacientes. 
Tabla 2. Resultados de las líneas celulares roja y blanca, antes y después del tratamiento de autohemoterapia mayor con ozono

\begin{tabular}{cccc}
\hline Parámetro & Antes & Después & Valores normales \\
\hline Eritrocitos $\times 10^{6} \mathrm{~mm}^{3}$ & 5.0 & 7.51 & 5.5 a 8.5 \\
Hemoglobina $(\mathrm{g} \%)$ & 12.1 & 15.8 & $12 \mathrm{a} 18$ \\
VG $(\%)$ & 38.0 & 49.2 & 37 a 55 \\
VGM $\left(\mu \mathrm{m}^{3}\right)$ & 69.0 & 66.0 & 60 a 77 \\
HGM $(\mathrm{pg})$ & 22.0 & 21.0 & 19 a 23 \\
CAGH $(\%)$ & 31.8 & 32.1 & 31 a 34 \\
RDW $(\%)$ & 14.9 & 13.7 & 14 a 17 \\
Leucocitos totales $/ \mathrm{mm}^{3}$ & 5900 & 11000 & 6000 a 18000 \\
Neutrofilos jóvenes $/ \mathrm{mm}^{3}$ & 118 & 770 & 0 a 540 \\
Neutrofilos segmentados $/ \mathrm{mm}^{3}$ & 3717 & 4730 & 3600 a 13860 \\
Neutrofilos totales $/ \mathrm{mm}^{3}$ & 3835 & 5500 & 3600 a 14400 \\
Eosinofilos $/ \mathrm{mm}^{3}$ & 59 & 2200 & 120 a 1800 \\
Monocitos $/ \mathrm{mm}^{3}$ & 177 & 550 & 180 a 1800 \\
Linfocitos $/ \mathrm{mm}^{3}$ & 1829 & 2750 & 720 a 5400 \\
\hline
\end{tabular}

Fuente: García et al., (2010)

Tabla 3. Grupo de perros con patologías musculo esqueléticas y sus respectivos tratamientos

\section{Grupo Tratamientos}

Primera sesión: Se utilizaron $5 \mathrm{ml}$ de mezcla oxígeno/ozono a una concentración de $8 \mu \mathrm{g} / \mathrm{ml}$ inyectado en articulaciones afectadas y puntos paravertebrales.

Segunda, tercera y cuarta sesión: Se aplicó plasma rico/pobre en

plaquetas (PRPP) + ozono a una concentración de $50 \mu \mathrm{g} / \mathrm{ml}$ en proporción 1:1 con el PRPP, inyectado en la fosa trocantérica.

Se inyecto ácido hialurónico $1 \mathrm{ml}$ en la fosa trocantérica.

Se inyecto 2-5 $\mathrm{ml}$ de mezcla oxígeno/ozono a concentración de 8 $\mu \mathrm{g} / \mathrm{ml}$ en zona periarticular y paravertebral.

\section{En las 4 sesiones se realizó autohemoterapia mayor con ozono.}

Se inyectaron de $2-5 \mathrm{ml}$ de mezcla oxígeno/ozono a una

G2 concentración de $8 \mu \mathrm{g} / \mathrm{ml}$ en las áreas dolorosas. Con repetición de la aplicación al tercer y al sexto día.

Fuente: Adaptado de Hernández, (2013). 
Castrini y Prignacca, (2002) evaluaron la efectividad de la mezcla oxígeno/ozono en el tratamiento de hernia discal en caninos, a los que se les realizaron un total de 10 sesiones, dos semanales por cinco semanas, el tratamiento fue mediante la inyección de la mezcla oxígeno/ozono a una concentración de $30 \mathrm{mg} / \mathrm{mL}$ por vía intramuscular paravertebral a la altura del espacio discal afectado. Después de la segunda sesión se observó una disminución en la sintomatología y al final del tratamiento se habían recuperado totalmente del déficit neurológico. De esta manera concluyeron que el ozono tiene una alta eficacia en el tratamiento de la hernia discal, que es una terapia muy asequible y además no invasiva.

En un reporte de caso hecho por Di Mauro y Smadelli, (2003) se utilizó la mezcla oxígeno/ozono en un perro Basset Hound macho de 5 años de edad diagnosticado con hernia discal a nivel del espacio intervertebral $L 4$ y $L 5$, mediante un examen mielográfico y una tomografía axial computarizada (TAC) (Figura 9), se administró $4 \mathrm{~mL}$ de la mezcla a una concentración de $25 \mathrm{mg} / \mathrm{mL}$ directamente en la hernia mientras se realizaba monitoreo tomográfico (Figura 10). Los resultados obtenidos 48 horas después de la administración fueron una notable mejoría en cuanto a los signos clínicos y la desaparición del déficit neurológico. Se le recomendó reposo al animal y limitación en el ejercicio.

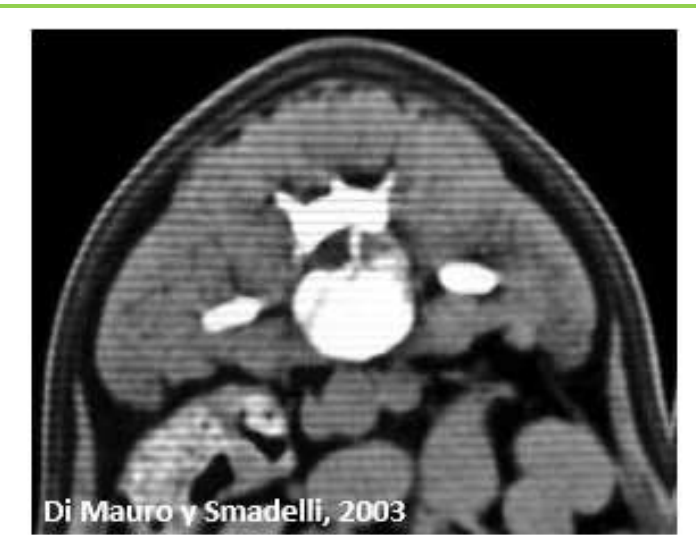

Figura 9. Diagnóstico de hernia discal paramedial derecha en L4-L5 mediante TAC.

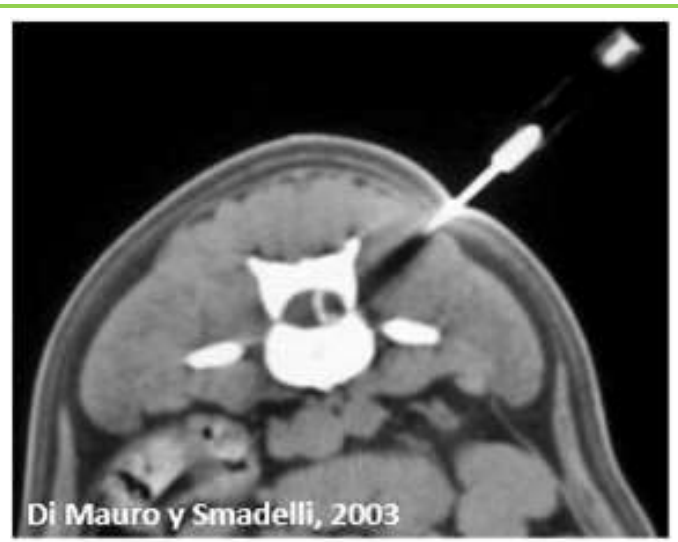

Figura 10. Verificación de la correcta administración del oxígeno/ozono en la hernia discal.

Fuente: Di Mauro y Smadelli, (2003). 


\section{ANÁLISIS Y DISCUSIÓN}

La ozonoterapia ha de ser considerada como un plan terapéutico coadyuvante contra enfermedades agudas, crónicas o que hayan sido tratadas anteriormente y que presenten recidivas, también es una excelente opción para combatir la resistencia que adquieren patógenos a los medicamentos convencionales como los antibióticos, por su efectiva acción germicida; de esta manera se asegura una mayor destrucción del agente causal de la enfermedad y se reduce la probabilidad de supervivencia que pudiera llegar a tener con solo la utilización del tratamiento alopático.

Es importante resaltar el vacío que aún existe en estudios e investigaciones de la ozonoterapia en Medicina Veterinaria, principalmente en los animales de compañía. Es muy reducida la literatura científica que se puede encontrar en internet y en bases de datos oficiales. Temas como la dosis/efecto en las diferentes especies no han sido tocados, es de importancia debido a la respuesta individual que pueden presentar y actualmente se extrapola las dosificaciones empleadas en la medicina humana. También se le suma el hecho de que no se han realizado estudios, o no han sido documentados, de la eficacia del ozono contra muchas otras enfermedades de tipo viral, bacteriano y parasitario que afectan a caninos y felinos.

\section{CONCLUSIONES}

El ozono es conocido por su acción germicida desde el siglo XIX donde era utilizado para la potabilización del agua para consumo humano y más adelante empleado en el tratamiento de enfermedades de origen bacteriano.

Los tratamientos con ozono han adquirido una mayor aceptación por la comunidad científica en los últimos años ya que se ha demostrado sus efectos cicatrizantes, inmunomoduladores, bactericidas, antimicóticos, analgésicos y antiinflamatorios.

La acción biológica del ozono en el organismo es causada por los metabolitos secundarios, las especies reactivas del oxígeno (ROS) y los productos de la 
oxidación lipídica (LOPS), que son el producto de la interacción del gas con sustancias biológicas presentes en el organismo.

Se ha logrado demostrar, mediante reportes de casos, los efectos positivos que genera la utilización del ozono como terapia para combatir algunas enfermedades que afectan a los animales de compañía.

La ozonoterapia presenta un amplio margen de seguridad en la terapéutica en pequeños animales, aunque las dosis empleadas sean las mismas que se utilizan en la medicina humana no se reportan efectos secundarios en los estudios. Es una opción asequible, en su relación costo/beneficio, tanto para el propietario como para el Médico Veterinario, quien tiene una opción más que sumarle a su arsenal terapéutico, aunque la ozonoterapia en veterinaria aún tiene un largo camino que recorrer en materia de estudios e investigaciones para poder brindarle una base más sólida que pueda apoyar los beneficios que le ofrece a los pequeños animales.

\section{REFERENCIAS BIBLIOGRÁFICAS}

1. Ballardini, E. Oxygen-ozone therapy for spinal muscle disorders in the horse. Rivista Italiana di Ossigeno-Ozonoterapia, 4 (1):70-73. 2005.

2. Bocci, V. Ozone a new medical drug. Ed. Springer, Norwell, U.S.A. 50 p. 2005.

3. Bocci, V., Aldinucci, C., Mosci, F., Valacchi, G. Ozonation of human blood induces a remarkable upregulation of heme oxygenase-1 and heat stress protein-70. Mediators of Inflammation, Art. 26785: 6 p. 2007. Disponible En: http://downloads.hindawi.com/journals/mi/2007/026785.pdf

4. Bocci, V., Zanardi, I., Michaeli, D., Travagli, V. Mechanisms of action and chemical-biological interactions between ozone and body compartments: A critical appraisal of the different administration routes. Current Drug Therapy. 4 (3): 159-173. 2009.

5. Borrego, A., Zamora, Z., González, R., Romay, C., Menéndez, S., Hernández, F., Montero, T., Rojas, E. Protection by ozone preconditioning is mediated by the antioxidant system in cisplatin-induced nephrotoxicity in rats. Mediators of Inflammation. 13 (1): 13-19. 2004.

6. Camps, A., Janine, D., Rosales, A., Rosete, M., Rodríguez, Y. Aplicación tópica de Oleozón ${ }^{\circledR}$ en la sarna psoróptica del conejo. Revista Veterinaria Argentina, 29 (293): $17 \quad$ p. $2012 . \quad$ Disponible https://www.veterinariargentina.com/revista/2012/09/aplicacion-topica-deloleozon-en-la-sarna-psoroptica-del-conejo/

7. Camps, A., Téllez, A., Valero, E. Efectos terapéuticos del oleozón en la piodermitis canina, considerando algunos procedimientos microbiológicos y 
micológicos. REDVET, Revista Electrónica de Veterinaria, 10 (12): 9 p. 2009. Disponible En: https://www.redalyc.org/pdf/636/63617155005.pdf

8. Cárdenas, N., Pedraza, J. Especies reactivas de oxígeno y sistemas antioxidantes: aspectos básicos. Educación Química, 17 (2): 164-173. 2006.

9. Castrini, A. Prignacca, E. Protocollo di trattamento dell'ernia discale con ossigeno-ozonoterapia nel cane. 2002. Disponible En: https://www.fisioterapiaveterinariapisa.it/articoli/ernia-discale-del-caneprotocollo/

10. Colín, A. Manual de uso de la ozonoterapia en perros. Tesis Médico Veterinario Zootecnista. Facultad de Medicina Veterinaria y Zootecnia, Universidad Autónoma del Estado de México, Toluca, México. 92 p. 2016.

11. Di Mauro, C. Smadelli, E. Infiltrazione intraerniaria di ossigeno-ozono con guida TC in un cane bassotto. Rivista Italiana di Ossigeno-Ozonoterapia, 2 (2): 179182. 2003.

12. Díaz, M., García, G., García, K., Sánchez, Y., Tillan, J. Evaluación de la irritabilidad dérmica, oftálmica y el efecto sensibilizante del OLEOZÓN ${ }^{\circledR}$ tópico. REDVET, Revista Electrónica de Veterinaria, 7 (11): 6 p. 2006. Disponible En: https://www.redalyc.org/pdf/636/63612653013.pdf

13. Fierro, A. Ozonoterapia en la medicina veterinaria. Vademécum Veterinario $10^{\mathrm{a}}$ Ed. Grupo Ediform, Ecuador, 3 p. 2011. Disponible En: https://quickvet.edifarm.com.ec//pdfs/articulos tecnicos/OZONOTERAPIA.pdf.

14. García, C., Prado, R., Moya, G., de Oliveira, N., Ferreira, L., Acciardi, I. The use of ozonated major autohemotherapy in canine ehrlichiosis treatment: case report. Revista CENIC. Ciencias Biológicas, 41: 7 p. 2010. Disponible En: https://www.redalyc.org/pdf/1812/181220509031.pdf

15. González, E. Ozonoterapia en flebología. Flebología y Linfología - Lecturas Vasculares, 7 (17): 1029-1033. 2012.

16. Hernández, M. Use of ozone and ozonated growth factors in musculoskeletal disorders of the canine species. Revista Española de Ozonoterapia, 3 (1): 9598. 2013.

17. Hidalgo, F., Torres, L. Ozonoterapia en medicina del dolor. Revisión. Revista de la Sociedad Española del Dolor, 20 (6): 291-300. 2013.

18. Kim, H., Noh, S., Han, Y., Kim, K., Kang, H., Kim, H. Park, Y. Therapeutic effects of topical application of ozone on acute cutaneous wound healing. Journal of Korean Medical Science, 24 (3): 368-374. 2009.

19. Kirchner, F. Tratamiento de las patologías discales y degenerativas de la columna vertebral con Plasma Rico en Factores de Crecimiento Plaquetario Ozonizados. Revista Española de Ozonoterapia, 2 (1): 91-106. 2012.

20. Larini, A., Bocci, V. Effects of ozone on isolated peripheral blood mononuclear cells. Toxicology in Vitro, 19 (1): 55-61. 2005.

21. Mauro, L. Manejo de la traqueobronquitis infecciosa canina (TIC) "Tos de las Perreras". REDVET, Revista Electrónica de Veterinaria, 7 (2): 9 p. 2006. Disponible En: https://www.redalyc.org/pdf/636/63612643015.pdf

22. Menéndez $\mathrm{S}$. Mecanismos de acción biológica y efectos terapéuticos del ozono. En: Menéndez, S., González, R., Ladea, O. E., Hernández, F., León, O. S., Díaz, M. (Eds.) Ozono: Aspectos Básicos y Aplicaciones Clínicas. La Habana: Ed. CENIC; p 4-107. 2008. 
23. Mondéjar, M., Rosas, L. Aplicación de ozonoterapia en pacientes con artritis reumatoide. In Crescendo. Institucional, 7 (1): 11-20. 2016.

24. Re, L., Martínez, G., Perez, G., Sirito, M. Role of ozone/oxygen in fibroblast growth factor activation. Discovering the facts. International Journal of Ozone Therapy, 9: 55-58. 2010.

25. Roberto, A. Plasma rico en plaquetas activado mediante el ozono como tratamiento en ligamentos colaterales de la articulación falangiana distal. Tesis Médico Veterinario. Facultad de Ciencias Veterinarias, Universidad de Buenos Aires, Buenos Aires, Argentina. 29 p. 2013.

26. Rubiano, A. Utilidad clínica de la ozonización de la sangre y sus componentes en equinos. Tesis de Médico Veterinario Especialista. Facultad de Ciencias Veterinarias, Universidad de Buenos Aires, Buenos Aires, Argentina. 76 p. 2015.

27. Salazar, M. Determinación del tiempo de cicatrización de heridas quirúrgicas en perros (Canis lupus familiaris) aplicando agua ozonificada en el Cantón San Miguel de Bolívar. Tesis Médico Veterinario Zootecnista. Facultad de Ciencias Agropecuarias Recursos Naturales y del Ambiente, Universidad Estatal de Bolívar. Guaranda, Ecuador. 87 p. 2014.

28. Schwartz, A. Ozonoterapia en la infección por virus del papiloma humano (HPV). Revista Española de Ozonoterapia, 7 (1): 5-16. 2017.

29. Schwartz, A., Martínez, G., Re, L. Factores de crecimiento derivados de plaquetas y sus aplicaciones en medicina regenerativa. Potencialidades del uso del ozono como activador. Биорадикалы и антиоксиданты, 3 (2): 27-44. 2016.

30. Vidal, L., Urruchi, W., Zamora, Z. Utilidad potencial de la ozonoterapia en la medicina veterinaria. REDVET, Revista Electrónica de Veterinaria, 10 (10): 13 p. 2009. Disponible En: https://www.redalyc.org/pdf/636/63617128017.pdf

31. Vigna, I., Menéndez, S. Ozone therapy application in different ophthalmologic diseases: study of 59 cases. RECVET, Revista Electrónica de Clínica Veterinaria, 2 (11): 9 p. 2007. Disponible En: https://www.austinozone.com/wpcontent/uploads/Ozone-therapy-application-in-different-ophthalmologicdiseases.pdf

32.Zamora, Z., Borrego, A., López, O., Delgado, R., González, R., Menéndez, S., Hernández, F., Schulz, S. Effects of ozone oxidative preconditioning on TNF- $\alpha$ release and antioxidant-prooxidant intracellular balance in mice during endotoxic shock. Mediators of Inflammation, 2005 (1): 16-22. 2005.

33.Zamora, Z., Menéndez, S., González C., Schulz, S. Efecto de la mezcla ozono/oxigeno combinado con levofloxacina en un modelo de sepsis peritoneal en rata. REDVET. Revista Electrónica de Veterinaria. 8 (9): 7 p. 2007. Disponible

En: https://www.researchgate.net/publication/26475862 Efecto de la mezcla ozo nooxigeno combinado con levofloxacina en un modelo de sepsis peritone al en rata Efect of ozoneoxygen mixture combined with levofloxacin in a model of peritoneal sepsis induced i

34.Zayas, K., Zamora, Z., Colunga, J., González, V. Efectividad de la ozonoterapia en un modelo experimental de hipersensibilidad bronquial en cobayo. REDVET, Revista Electrónica de Veterinaria, 10 (12): 15 p. 2009. Disponible En: https://www.redalyc.org/pdf/636/63617155006.pdf 